\title{
Perceived Risk of COVID-19 Pandemic: The Role of Public Worry and Trust
}

\author{
Mohsen Khosravi ${ }^{1 \star}$
}

${ }^{1}$ Department of Psychiatry and Clinical Psychology, Baharan Psychiatric Hospital, Zahedan, Sistan and Baluchistan, IRAN ${ }^{\star}$ Corresponding Author: m.khosravi@zaums.ac.ir

Citation: Khosravi M. Perceived Risk of COVID-19 Pandemic: The Role of Public Worry and Trust. Electron J Gen Med. $2020 ; 17(4):$ em203. https://doi.org/10.29333/ejgm/7856

\section{ARTICLE INFO}

Received: 23 Mar. 2020

Accepted: 26 Mar. 2020

In late December 2019, an outbreak of the novel coronavirus disease (COVID-19) was started in Wuhan, China, and quickly reached the other countries of the world (1). In comparison with the other members of coronaviruses family such as SARS-CoV and MERS-CoV, COVID-19 appears to have a lower fatality rate (virulence). However, the high transmission rate of this virus, as well as the lack of vaccines and certain pharmaceutical treatments for COVID-19 have posed serious challenges to the control of the disease spread (1-3). To tackle such problems, it is necessary to implement non-medical measures such as the promotion of personal protection practices (e.g. use of face masks and following personal hygiene), imposing travel restrictions, and maintaining social distance from possibly infected cases. To achieve the successful implementation of such measures recommend by public health authorities, the willingness of the public plays an important and decisive role. However, it is still a health problem to encourage the public to unconditionally follow these recommended preventive actions. People's risk perception of pandemic is one of the factors contributing to an increase in public participation in adopting preventive measures (4-6). According to the Protection Motivation Theory (PMT), the intention of the general public to adopt protective measures is significantly influenced by high levels of perceived risk. The theory posits that public perception of the severity and vulnerability to a certain health threat determines their risk perception about a disease (7). Therefore, during a new pandemic, getting information from various sources, such as public health professionals, the government, and the media, can increase people's awareness about the risk, and consequently, their adoption of preventive measures (4). However, several factors might affect the subjects' perception of their actual risk for disease. This discussion aims to investigate the role of public worry and trust in the perceived risk of the COVID-19 pandemic.

The worry over getting a disease can influence the perceived risk of a pandemic. It is an affective emotional response to a threat, which can predict protective behaviors independent of the risk severity. In other words, worrying is a predictor for the individual's behaviors when facing a threat. Various factors, including socio-demographic characteristics, social context, and individual values can affect worry about a pandemic $(8,9)$. Based on recent studies, being older, female, more educated, and non-white are associated with a higher chance of adopting the protective behaviors (10). Note that the worry over a threat doesn't occur in a vacuum; rather under a circumstance where individuals might be quickly influenced by the emotional reactions of others. This reveals a strong correlation between perceiving the anxieties of family and friends, and personal concern (8). In any stage of a pandemic, practitioners must be aware of the rumors going around and the potential risk of "emotional contagion" among populations $(8,11)$. Also, the social context may affect the experienced levels of worry. For instance, the low-income class is more concerned with issues such as the equal and fair distribution of health services. Thus, during a pandemic, such class may experience emotional responses to health risks, more risk perceptions, increased negative emotions expressions such as anger or fear, and huge challenges to the risk reduction (9). Another factor affecting public worry includes conservation values such as security, conformity, and tradition. Individuals who emphasize conservation values would carefully put preventive measures into practice. Whereas people with the opposite values (e.g. high self-direction, stimulation, and hedonism based on Schwartz's model) pay less attention to the desirable behavior (8).

One more factor that contributes to shaping an accurate risk perception of disease is trust. According to the Trust and Confidence Model, trust plays an important part in managing a threat by affecting the public's judgments about the risks and the related benefits. It can indirectly impact the adoption of the recommended measures. Trust is believed as the main core of hearing, interpreting, and responding to public health messages. This has resulted in a growing dependency of the effective risk and crisis communication on the method of receiving information and the level of trust in the government during the pandemic period. Therefore, governments must provide complete information about the pandemic to maintain 
public trust, even when the information is very limited. Governments must never downplay the reality of risk and vulnerabilities to reduce public fears and worries. Besides, contradictory information maintains by the government can be associated with reduced public trust. Recent studies found that in a pandemic, governments must consider that healthcare workers and municipal health services are among the most trusted information sources during the process of providing information. The media has the lowest trust position in such an event $(4,12)$.

Since major coronavirus outbreaks often occur in waves, surviving the first wave may be accompanied by a misleading sense of immunity. Moreover, worrying about the infection may change rapidly during the course of a disease. For instance, due to people's concern about a specific behavior (e.g. vaccination), they may be encouraged to examine that behavior. However, this behavioral action would reduce the levels of worry in later stages. Such a case, therefore, "can lead to apparently conflicting worry-behavior correlations" (8).

The results show that public initial emotional concerns and trust can play an essential role in improving the perceived risk of a pandemic and increasing public participation in adopting preventive measures. Therefore, practitioners can utilize and develop these models of responding to a pandemic when facing newly emergent threats.

\section{REFERENCES}

1. Xu Z, Shi L, Wang Y, Zhang J, Huang L, Zhang C, et al. Pathological findings of COVID-19 associated with acute respiratory distress syndrome. Lancet Respir Med. 2020. https://doi.org/10.1016/S2213-2600(20)30076-X PMID: 32085846

2. Lai CC, Shih TP, Ko WC, Tang HJ, Hsueh PR. Severe acute respiratory syndrome coronavirus 2 (SARS-CoV-2) and corona virus disease-2019 (COVID-19): the epidemic and the challenges. Int J Antimicrob Agents. 2020;55(3):105924. https://doi.org/10.1016/j.ijantimicag.2020.105924 PMID: 32081636

3. Abdulamir AS, Hafidh RR. The Possible Immunological Pathways for the Variable Immunopathogenesis of COVID19 Infections among Healthy Adults, Elderly and Children. Electron J Gen Med. 2020;17(4):em202. https://doi.org/ $10.29333 /$ ejgm/7850
4. van der Weerd W, Timmermans DR, Beaujean DJ, Oudhoff $J$, van Steenbergen JE. Monitoring the level of government trust, risk perception and intention of the general public to adopt protective measures during the influenza $A(\mathrm{H} 1 \mathrm{~N} 1)$ pandemic in the Netherlands. BMC public health. 2011;11(1):575. https://doi.org/10.1186/1471-2458-11-575 PMID: 32081636 PMCID: PMC3152536

5. Cowling BJ, Ng DM, Ip DK, Liao Q, Lam WW, Wu JT, et al. Community psychological and behavioral responses through the first wave of the 2009 influenza A (H1N1) pandemic in Hong Kong. J Infect Dis. 2010;202(6):867-76. http://doi.org/10.1086/655811 PMID: 20677945

6. Ibuka Y, Chapman GB, Meyers LA, Li M, Galvani AP. The dynamics of risk perceptions and precautionary behavior in response to 2009 (H1N1) pandemic influenza. BMC Infect Dis. 2010;10:296. https://doi.org/10.1186/1471-2334-10296 PMID: 20946662 PMCID: PMC2964717

7. Rogers RW. A protection motivation theory of fear appeals and attitude change1. J Psychol. 1975;91(1):93-114. https://doi.org/10.1080/00223980.1975.9915803 PMID: 28136248

8. Goodwin R, Gaines SO, Myers L, Neto F. Initial psychological responses to swine flu. Int J Behav Med. 2011;18(2):88-92. https://doi.org/10.1007/s12529-010-9083-z PMID: 20195809 PMCID: PMC7090401

9. Vaughan E, Tinker T. Effective health risk communication about pandemic influenza for vulnerable populations. Am J Public Health. 2009;99(S2):S324-32. https://doi.org/ 10.2105/AJPH.2009.162537 PMID: 19797744 PMCID: PMC4504362

10. Bish A, Michie S. Demographic and attitudinal determinants of protective behaviours during a pandemic: a review. $\mathrm{Br} \mathrm{J}$ Health Psychol. 2010;15(4):797-824. https://doi.org/10.1348/135910710X485826 PMID: 20109274

11. Goodwin R, Haque S, Neto F, Myers LB. Initial psychological responses to Influenza A, H1N1 ("Swine flu”). BMC Infect Dis. 2009;9(1):166. https://doi.org/10.1186/1471-2334-9166 PMID: 19807908 PMCID: PMC2765446

12. Siegrist $M$, Zingg A. The role of public trust during pandemics. Eur Psychol. 2014;19(1):23-32. https://doi.org/ 10.1027/1016-9040/a000169 